\title{
Supplementation of Aloe Vera Extract in Lactating Goats Diet: Effects on Rumen Fermentation Efficiency, Nutrient Utilization, Lactation Performance and Antioxidant Status
}

\author{
Praveen Sivakumara Banakar \\ NDRI: National Dairy Research Institute \\ Sachin Kumar \\ National Dairy Research Institute \\ V V Vinay \\ National Dairy Research Institute \\ Sonam Dixit \\ National Dairy Research Institute \\ Nitin Tyagi \\ National Dairy Research Institute \\ Amrish Tyagi ( $\square$ amrishtyagi1963@yahoo.com ) \\ NDRI: National Dairy Research Institute
}

\section{Research Article}

Keywords: Aloe vera, Lactating goats, Antioxidant, Milk yield, Propionic acid

Posted Date: June 21st, 2021

DOI: https://doi.org/10.21203/rs.3.rs-599373/v1

License: (c) (i) This work is licensed under a Creative Commons Attribution 4.0 International License.

Read Full License 


\section{Abstract}

The present work was conducted to investigate the effects of supplementing aloe vera extract on rumen fermentation efficiency, nutrient utilization, lactation performance and antioxidant status of goats. Twenty-four crossbreed lactating goats (Alpine $\times$ Beetal) were divided into three experimental groups (AV0, AV2 and AV4). AV0 had no supplementation, group AV2 and AV4 received ready to feed aqueous extract of aloe vera at 20 and $40 \mathrm{~g} / \mathrm{kg}$ dry matter intake, respectively, along with basal diet and experiment lasted for 100 days. Average DMI did not vary $(P>0.05)$ among treatment groups; however, the cumulative metabolic bodyweight of AV4 was significantly lower $(P<0.05)$ than the AV0 and AV2 groups (AV0 = AV2 > AV4). Intake and digestibility of DM, OM, CP, NDF, ADF, and EE was unaffected $(P>$ $0.05)$ by aloe vera supplementation. The milk production, yield of milk fat, protein, lactose and solids not fat (SNF) of goats in the AV4 group was significantly higher $(P<0.05)$ than other groups $($ AV4 $>$ AV2 $=$ AV0). The activity of superoxide dismutase and catalase and levels of plasma ferric reducing total antioxidant power were high $(P<0.01)$ in the aloe vera supplemented group (AV4 = AV2 > AV0). There was no significant difference $(P=0.979)$ in the $\mathrm{pH}$, acetic acid $(P=0.449)$, butyric acid $(P=0.864)$ concentration of the rumen liquor among the treatment groups. The propionic acid concentration was similar between AV2 and AV4 and significantly higher $(P=0.024)$ than the AV0 group (AV4 = AV2 > AV0). Moreover, C2:C3 values were significantly lower $(P=0.037)$ in the AV4 group compared to the Control (AV0). Thus, aloe vera supplementation enhanced milk yield, propionic acid production, and antioxidant status without affecting nutrient utilization; however, results were better in the AV4 group. The inclusion of aloe vera at $40 \mathrm{~g} / \mathrm{kg}$ of DMI would improve the rumen fermentation efficiency, lactation performance and overall health status of the dairy goats.

\section{Introduction}

The instigation of the one-health notion has gained paramount importance for food safety, food security, and sustainable food production systems (Garcia et al., 2020). One health is a multidisciplinary holistic approach, where the health of humans, animals, and the environment are inextricably linked (Lainé and Morand, 2020). Globally, sustainable food production systems are required to ensure the complexity and scale of food safety and security to feed a growing population (King et al., 2017). Animals reared for food production undergo tremendous stress due to the cascade of events occurring around the parturition and lactation period; consequently, compromising their immunity and further exposure to diseases (Colitti et al., 2019). Application of conventional antimicrobials agents to combat infections and upsurge production has been standard practice in farm animals rearing (Singh et al., 2021a; Mann et al., 2021). However, growing concerns about in-feed antibiotic usage due to their devastating effects caused by the emergence of multidrug-resistant pathogens have led to antibiotics ban by the European Union and other countries (Singh et al., 2021 b; Benchaar, 2021). A paradigm shift has driven animal nutritionists to look for safe and natural feed additives to conventional antimicrobials for sustainable animal production with one health concept in consideration (Huang et al., 2018). Several newer emerging feed additives, which can be used as an alternative to antibiotics, have been suggested within the livestock industry. One such 
category gaining interest is natural phytogenic feed additive (PFA) (Banakar et al., 2019), which leaves no residue in the animal products (Zhou et al., 2020), or its presence in minor quantity increases its nutraceutical value (Santos et al., 2017) and further strengthening animal antioxidant status making resilient to stress (Suman et al., 2015).

Plant-derived products or the plant secondary metabolites (PSMs) viz essential oils, saponins, condensed tannins, flavonoids, and phenolic compounds, forms the major constituents of PFAs (Frutos et al., 2020). Cumulative research findings indicate that PSMs at appropriate levels modulate protozoal populations, increases bacterial and fungal abundance. This results in higher propionate production, increases microbial yield, reduces methanogenesis and enhances productive performance in ruminants (Banakar et al., 2019). As revealed in scientific literature, this shift in the fermentation pattern is primarily ascribed to the antimicrobial and antioxidant properties of PFAs that boost animal health which in turn enhance production performance (Huang et al., 2018).

Aloe vera (AV) is one such source of PSMs that comprises the potential properties of PFAs. Aloe barbadensis Mill is the scientific name of AV commonly found in India, which belongs to the Aloeaceae family (Sánchez-Machado et al., 2017). Aloe vera is used in ethnoveterinary medicine and has a positive impact on animal health and welfare. Around 75 bioactive compounds are identified in aloe vera extract. Anthraquinones, polyphenols, and polysaccharides are among the major constituents, whereas vitamins (a-tocopherol, $\beta$-carotene, and folic acid) and minerals constitute the minor components (Kumar et al., 2019). Various in vitro studies report antioxidant, anti-inflammatory, and antimicrobial properties of AV (Lucini et al., 2015), indicating the potential of AV to modulate the animals' rumen fermentation and health status. Besides, in vivo studies of AV supplementation carried out in monogastric animals (poultry and swine) revealed its nutrigenomic effect on animal products and animal welfare (Darabighane et al., 2011; Ghasemi-Sadabadi et al., 2020). However, there are no in vivo studies in ruminants reporting its interaction with the animals' rumen fermentation and it is a source of interest. The present work was designed to investigate the effects of supplementing aloe vera extract on rumen fermentation efficiency, nutrient utilization, lactation performance and antioxidant status of goats.

\section{Materials And Methods}

\section{Lactating goats and experimental diets}

Twenty-four crossbreed lactating goats (Alpine $\times$ Beetal) were selected after ten days of parturition, i.e., early to mid-lactation period, from the Livestock Research Center, NDRI, Karnal. Based on the average body weight $(37.28 \pm 1.69 \mathrm{~kg})$ and the milk yield $(1776.21 \pm 93.21 \mathrm{~g} /$ day $)$, animals were randomly assigned into three groups of 8 animals each. Goats were fed with a basal diet containing berseem and concentrate mixture (60:40) to fulfill the animals' nutrient requirement (ICAR, 2013). The ingredients' composition and chemical composition of the diets are presented in Tables 1 and 2, respectively. Goats were housed in well-ventilated pens with individual animal feeding arrangements and had $24 \mathrm{hr}$ free access to water. After an adaptation period of 10 days, the animals were switched over to their respective 
experimental diets for 90 days. Group I (AV0) had no supplementation, animals in Group II (AV2) and Group III (AV4) received ready to feed aqueous extract of aloe vera (procured from Herbal consultant ${ }^{\circledR}$, India) at 20 and $40 \mathrm{~g} / \mathrm{kg}$ dry matter intake, respectively ( $2 \%$ and $4 \%$ of $\mathrm{DMI})$, along with basal diet.

\section{Data recording}

The experimental animals' daily dry matter intake (DMI) was recorded by assessing the dry matter of diet offered and residue left. Also, the lactating goats' daily milk yield and fortnightly body weight were measured using an automated electronic weighing scale. Metabolic body weight was calculated using the formula, $B W^{\wedge 0.75}$.

\section{Sample collection}

Feed samples were collected daily to ascertain the DMI of individual lactating goats after assessing the dry matter of feed offered and residue left. Milking of individual animals was carried out twice daily, i.e., at 5:30 AM and 3:00 PM. The sampling (1/100 th of milk yield) was done at every fortnight interval from each milking and analyzed immediately for composition. Blood was collected from the jugular vein in a sterile vacutainer containing acid citrate dextrose as an anticoagulant on the $0,30,60$, and $90^{\text {th }}$ day of the experiment. At the end of the investigation, $200 \mathrm{~mL}$ of rumen liquor was collected using a rumen liquor collection pump to estimate the $\mathrm{pH}$ and individual volatile fatty acids (IVFA). A digestion trial of a 7$\mathrm{d}$ collection period was conducted to evaluate the apparent nutrients' digestibility. Total feces from individual animals were collected in plastic containers and mixed thoroughly to obtain a composite sample. Part $\left(1 / 1000^{\text {th }}\right)$ of the total collected feces was acidified with $\mathrm{H}_{2} \mathrm{SO}_{4}$ for nitrogen estimation.

\section{Sample processing and analysis}

\section{Proximate analysis and apparent nutrient digestibility}

Representative feces and feed (offered and residue) samples were oven-dried at $60^{\circ} \mathrm{C}$ for $48 \mathrm{~h}$, ground, and passed through $1 \mathrm{~mm}$ sieve and stored in a ziplock plastic bag till analysis. Dry matter (DM), organic matter (OM), crude protein (CP), ether extract (EE), neutral detergent fibre (NDF) and acid detergent fibre (ADF) were estimated as per the standard procedures of the Association of Official Analytical Chemists (AOAC, 2010). Apparent digestibility was calculated using the formula (Singh et al., 2021a):

Apparent digestability $(\%)=$ Nutrient intake - Nutrient output/Nutrient intake $\times 100$

\section{Milk components}

Milk composition was determined using a pre-calibrated automatic milk analyzer (Lactostar, FUNKE GERBER, Berlin) to calculate the yield of milk fat, protein, lactose and solids not fat (SNF)

\section{Animals' antioxidant status}


Collected blood samples were immediately transferred to a laboratory with a cold chain maintained at $4^{\circ} \mathrm{C}$ and centrifuged at $3000 \mathrm{rpm}$ for 10 mins to separate plasma from packed erythrocytes. The erythrocyte antioxidant enzyme activity and ferric reducing total antioxidant power (FRAP) were estimated using RBC hemolysate (prepared from the packed erythrocytes) and plasma, respectively. Antioxidant enzyme activity such as catalase (Aebi, 1984), SOD (Madesh and Balasubramanian, 1998), and GPx (Paglia and Valentine, 1967) were determined spectrophotometrically (Specord 200, Germany) within two days after collection and processing of blood. FRAP assay was performed as described by Prakova et al. (2010).

\section{Rumen liquor pH}

Immediately after collecting rumen liquor, it was strained through double layered muslin cloth to measure $\mathrm{pH}$ using an electronic $\mathrm{pH}$ meter (pH Spear, EC- PHWPSEN04; Eutech instruments, Malaysia), calibrated against standard buffer solutions.

\section{Individual volatile fatty acid estimation}

For estimating IVFA, strained rumen liquor samples were preserved by adding $0.2 \mathrm{ml}$ of $25 \%$ metaphosphoric acid per $\mathrm{ml}$ of rumen liquor (RL). Then samples were centrifuged (5000 rpm for $20 \mathrm{~min}$ ) after $2 \mathrm{~h}$ of the stand at $4{ }^{\circ} \mathrm{C}$ and the supernatant was used for estimation of IVFAs. The aliquot $(3 \mu \mathrm{l})$ was injected using $10 \mu \mathrm{l} \mathrm{Hamilton} \mathrm{syringe} \mathrm{(Hamilton,} \mathrm{Nevada,} \mathrm{USA)} \mathrm{into} \mathrm{Gas} \mathrm{chromatograph} \mathrm{(GC,} \mathrm{Nucon}$ 5700, Nucon Engineers, New Delhi) equipped with a flame ionization detector and stainless steel column packed with Chromosorb -101 mesh 80-100 as described by Miri et al. (2015). For fractionation of IVFA, analytical conditions were as follows: Injection port temperature, $250^{\circ} \mathrm{C}$; column temperature, $190^{\circ} \mathrm{C}$ and detector temperature, $260^{\circ} \mathrm{C}$. The flow rate of nitrogen (carrier gas) was maintained at $40 \mathrm{ml} / \mathrm{min}$, hydrogen at $30 \mathrm{ml} / \mathrm{min}$ and air, $300 \mathrm{ml} / \mathrm{min}$. Based on the retention time and their concentration $(\mathrm{mM})$, different IVFA's of each sample were identified and calculated by comparing the retention time as well as the peak area of standards after deducting the corresponding blank values.

\section{Statistical analysis}

Data collected were analyzed using General Linear Model (GLM) by the Analysis of Variance (ANOVA) method of the Statistical Package for the Social Sciences (SPSS, v21.0; Chicago, IL, USA). The following statistical model was used:

$Y_{i j k}=\mu+D_{i}+P_{j}+(D \times P)_{i j}+e_{i j k}$

where, $\mathrm{Y}_{\mathrm{ijk}}=$ dependent variable

$\mu=$ overall mean

$D_{i}=$ effect of $i_{\text {th }}$ dietary treatment 
$P_{j}=$ effect of $j_{t h}$ period

$(D \times P)_{i j}=$ interaction effect of $i_{t h}$ dietary treatment with $j_{\text {th }}$ period

$\mathrm{e}_{\mathrm{ijk}}=$ casual effect of each observation.

One-way ANOVA was performed for nutrient intake, apparent digestibility of nutrients and rumen liquor parameters. DMI, bodyweight changes, production performance parameters, antioxidant enzyme activity and FRAP values were analyzed using Two-way ANOVA. Duncan's multiple range test was used for the pair-wise comparison of means. GraphPad Prism 8.1 (San Diego, CA, USA) was used to develop figures. The effects were considered significant at $P<0.05(*)$ and high statistical significance at $P<0.001(* *)$, whereas non-significance at $P>0.05$.

\section{Results}

\section{Dry matter intake and metabolic body weight changes}

The fortnightly DMI and metabolic body weight changes of goats are depicted in Figure 1. Periodic changes in the DMI varied significantly $(P<0.001)$ in all the treatment groups. There was a remarkable decrease $(P<0.05)$ in the DMI of the AV4 group in the first fortnight in comparison to Control (AV0) and AV2 groups. However, this decrease in DMI got nullified in the subsequent weeks. As a sequela of the changes in $\mathrm{DMl}$, metabolic body weight changes displayed significant treatment $(P=0.002)$ and periodic changes $(P=0.026)$ in different groups. Goats in the AV4 group exhibited decreased $(P<0.05)$ metabolic body weight than AV2 and AVO group in the first fortnight; however, the values remained similar in the subsequent fortnights. Nevertheless, average DMI did not vary $(P>0.05)$ among treatment groups (Table 3 ); on the contrary, the cumulative metabolic bodyweight (Table 3) of AV4 was significantly lower $(P<$ $0.05)$ than the AV0 and AV2 groups (AV0 = AV2 > AV4).

\section{Nutrient intake and their apparent digestibility}

Nutrient intake and the apparent digestibility of dietary treatment groups are presented in the Table 3 . Dry matter intake $(\mathrm{kg} / 100 \mathrm{~kg} \mathrm{BW})$ was similar $(P>0.05)$ among treatment groups during the digestion trial; however, values were numerically higher in AV2 and AV4 than in the AV0 group. Intake of OM, CP, NDF, $\mathrm{ADF}$, and EE was unaffected $(P>0.05)$ by aloe vera supplementation. Likewise, we did not observe the influence $(P>0.05)$ of treatment diets on the apparent digestibility (\%) of DM, OM, CP, NDF, ADF, and EE among different groups.

\section{Milk yield and milk components}

The average milk and milk components yield are given in Table 4. Treatment $(P=0.001)$ and periodic changes $(P<0.001)$ were observed in milk yield (Figure 2$)$ among treatment groups. There was an increase in milk yield of AV2 and AV4 groups over Control (AV0) since the third fortnight of aloe vera supplementation. During the experimentation period, the milk yield of AV4 was the highest, followed by 
AV2 and AV0 (AV4 > AV2 $\geq A V 0$ ). Cumulatively, over the whole experimental period, the milk yield of goats in the AV4 group was statistically higher $(P<0.05)$ than AV2 and AV0 group (AV4 > AV2 = AV0). Similarly, the yield of milk fat, protein, lactose and solids not fat (SNF) was significantly higher $(P<0.05)$ in the AV4 group compared to AV2 and AV0 group.

\section{Antioxidant status}

The periodic changes and the cumulative values of erythrocyte antioxidant enzyme activities are shown in Figure 3 and Table 5. There was a significant increase $(P<0.001)$ in erythrocyte SOD and catalase enzyme activity in AV2 and AV4 groups over AV0 since the first month of aloe vera supplementation and followed the trend of AV4 > AV2 $\geq$ AV0 throughout the experiment. Moreover, significant $(P<0.001)$ periodic variations were observed in SOD, catalase activity, and FRAP values in all the treatment groups. Furthermore, over the whole experimental period, the activity of SOD and catalase was higher $(P<0.01)$ in the 2 and $4 \%$ aloe vera supplemented group than in the Control (AV4 = AV2 > AV0). Nevertheless, we could not comprehend any perceivable difference $(P>0.05)$ in the activity of GPx among the treatment groups. Aloe vera supplementation had a significant influence $(P<0.001)$ on the total antioxidant activity expressed in FRAP terms, which followed the same trend as SOD and catalase. Overall, cumulative values of FRAP were significantly higher $(P<0.001)$ in AV2 and AV4 than in the control group.

\section{The individual volatile fatty acid and $\mathrm{pH}$ of rumen liquor}

Data on IVFA ( $\mathrm{mmol} / \mathrm{L})$ and $\mathrm{pH}$ of the rumen liquor are presented in Table 6 . There was no significant difference $(P=0.979)$ in the $\mathrm{pH}$ of the rumen liquor among the treatment groups. Among the IVFA, acetic acid (C2) tended to decrease with the graded level of aloe vera supplementation (AV2 and AV4) but it was statistically non-significant $(P=0.449)$. Similarly butyric acid $(C 4)$ concentration did not vary $(P=0.864)$ among different groups. The propionic acid concentration was similar between AV2 and AV4 and significantly higher $(P=0.024)$ than AV0 group (AV4 $=$ AV2 $>$ AV0). Also, C2:C3 values were significantly lower $(P=0.037)$ in AV4 group compared to control (AV0).

\section{Discussion}

Palatability of feed is directly correlated with voluntary feed intake (VFI) of animals. Levels of tannins or polyphenols influence the palatability of feed and, in turn, its VFI (Frutos et al., 2004; Patra and Saxena, 2011). DMI of $4 \%$ aloe vera supplemented group decreased in the first fortnight, though subsequent fortnights did not show a significant difference in the DMI. Present findings may be due to the short-term influence of the astringency effect (Landau et al., 2000) of aloe vera polyphenols or tannins during the adaptation period. Similar to DMI, fortnightly metabolic bodyweight changes followed the same trend. Since the nutrient intake during the first fortnight did not satisfy the animal's requirement (maintenance and lactation), a decrease in the bodyweight was observed. However, there was a steady intake of DM in the subsequent fortnight, resulting in increased body weight as the lactation progressed. It is well noted that with a low to moderate level of tannins in the diet, VFI remains unchanged. However, when tannins rich diet is introduced to the animals, it may take some time for them to adjust to the new diet (Frutos et 
al., 2020). Nonetheless, goats have the capacity to degrade tannins (Correddu et al., 2020) and ability to make it less astringent by secreting tannin binding proline-rich proteins in the saliva (Frutos et al., 2004). Our findings are in line with Buccioni et al. (2015b), (2017), Rana et al. (2012), Suman et al. (2015), and Toral et al. (2011), who found no significant difference in the total dry matter intake with tannins or polyphenols levels varying between $1 \mathrm{~g}$ to $40 \mathrm{~g} / \mathrm{kg}$ diet.

In the current research work, $D M, O M, C P, E E, N D F$ and $A D F$ intake and digestibility remained unchanged $(P>0.05)$. Our results agree with Holtshausen et al. (2009), who observed no significant difference in DM, CP, NDF and ADF's apparent digestibility on supplementing Yucca schidigera and Quillaja saponaria at 10 $\mathrm{g} / \mathrm{kg}$ of DM. Similarly, Rana et al. (2012) reported no change in the CP, NDF and ADF digestibility when tannin-rich Terminalia chebula was included in the diets ( 0.59 and $1.79 \%$ of DM) of kids.

Nevertheless, Hristov et al. (2013) found that DMI reduced in lactating Holstein Friesian cows with the inclusion of oregano at different levels $(0,250,500,750 \mathrm{~g} /$ day $)$ in the diet; however, digestibility of nutrients was unaffected.

Aloe vera has bioactive compounds such as flavonoids and polyphenols that exhibit potent antioxidant, anti-inflammatory, and antimicrobial activity. These bioactive compounds can quench free radicals and activate antioxidant enzymes like catalase, SOD, and GPx to prevent oxidative stress (Danish et al., 2020; Kumar et al., 2019; Maan et al., 2018; Sánchez-Machado et al., 2017). Nonetheless, activation of the antioxidant system by bioactive compounds is more pronounced during stressful conditions (Rubió et al., 2013). Lactating animals undergo a state of oxidative stress, i.e., the disparity between animals' antioxidant status and oxidants, especially after calving, early and mid-lactation stages (Berchieri-Ronchi et al., 2011; Sharma et al., 2011). Stress mainly prevails because of the metabolic and physiological changes occurring after kidding and during lactation.

Consequently, to counteract oxidative stress, there will be changes in the antioxidant enzyme activity, which is evident in the current study. Significantly higher values of antioxidant enzyme activity in aloe vera supplemented groups point to its potential for easing oxidative stress (Huang et al., 2018) during the lactation period. Ferric reducing total antioxidant power (FRAP) is another parameter that provides essential information on the animal's antioxidant status, explaining the imbalance between pro-oxidants and antioxidants (Ghiselli et al., 2000). Aloe vera supplemented groups displayed higher FRAP values than Control which further strengthens the fact that aloe vera has a beneficial role in combating oxidative stress.

Current findings are in line with Zhong et al. (2012), who observed an increase in the total antioxidant capacity and SOD activities in plasma of lambs fed with Astragalus membranaceus root and Astragalus polysaccharide. Similarly, Fructus Ligustri Lucidi's inclusion in the sheep diet improved the animal's antioxidant status by enhancing SOD and glutathione reductase (Qiao et al., 2012). Suman et al. (2015) reported an increase in the erythrocyte SOD and catalase activity and increased plasma FRAP value when fed with a tanniniferous Terminalia chebula plant extract-based diet in goats. 
Production performance (reproduction and milk production) of the dairy animals depends on the overall well-being (Gross and Bruckmaier, 2019). During the lactation period, external or abiotic (environmental) and internal or biotic (metabolic) stressors may have adverse effects on animal health (Colitti et al., 2019). Under such conditions, the animal homeorhetic system may repartition nutrients towards maintenance, resulting in a transient decrease in milk production. (Bradford et al., 2015; Bruckmaier and Gross, 2017). However, the animal can recover if the stressors are lessened for overall well-being and when an animal gets the required nutrients (Sordillo and Aitken, 2009) for metabolic adaptation resulting in sustained milk production. The better antioxidant status of the lactating goats in the aloe vera supplemented group contributes to the animal's welfare; it might have resulted in a high overall milk yield compared to the non-supplemented group (Maheswari et al., 2021). As reported by Liu et al. (2013), condensed tannins ( $10 \mathrm{~g} / \mathrm{kg}$ of DM) in the diet of transition dairy cows alleviate oxidative stress and increase the antioxidant status by inhibiting lipid peroxidation and enhancing the antioxidant enzyme activity.

Furthermore, the increase in propionic acid production in the present study might have improved milk production in the $4 \%$ aloe vera supplemented group. In the current investigation, a decreasing trend in acetic acid concentration and $\mathrm{C} 2: \mathrm{C} 3$ might have increased glucose production and improved fermentation efficiency and is reflected in milk production. As a consequence of the increased milk production, the milk fat, protein, lactose, and SNF yield were high in the $4 \%$ aloe vera supplemented group. Our findings are consistent with Buccioni et al., 2015b, who observed an increase in the average milk yield with tannins ( $80 \mathrm{~g} / \mathrm{kg} \mathrm{DM})$ in the dairy ewes' diet. Similar results are reported by Tekippe et al. (2011) (oregano leaf), Heidarian Miri et al. (2013) (Cumin extract, 2.53\% DMI) and Zhou et al. (2020) (Piper sarmentosum extract, $1,200 \mathrm{mg} / \mathrm{kg} \mathrm{DM}$ ) with the plant extracts in the diet of dairy animals. However, at the same time, no effects on milk yield have been reported on inclusion of tannins or polyphenols, or herbal mixture in the diet of dairy animals (Moate et al., 2014; Jain et al., 2013, and Hristov et al., 2013; Buccioni et al., 2015a).

Overall, researchers contrasting findings could be due to 1) variations in the sources of PSMs; 2) the composition of polyphenols or bioactive compounds in the diet; 3 ) animal species. Nevertheless, low to moderate levels of tannins or polyphenols in the diet of dairy animals did not affect the animals' overall performance.

\section{Conclusions}

Dietary inclusion of aloe vera extract did not affect the overall dry matter intake, nutrients intake and apparent digestibility. However, milk yield increased in the $4 \%$ aloe vera supplemented group by improving the overall health status of the animals, which is evident in the increased antioxidant status of the animal. Increased propionic acid production and decreased C2:C3 in supplemented groups indicate the beneficial effect on rumen fermentation efficiency. Based on these results, we surmise that dietary supplementation of aloe vera at $40 \mathrm{~g} / \mathrm{kg}$ of DMI would improve the overall health status, rumen fermentation efficiency and lactation performance of the dairy goats. 


\section{Declarations}

\section{Author contribution}

BPS, SK, AKT: Conceptualization, Data curation, Funding acquisition, Investigation, Methodology, Project administration, Validation, Writing - original draft, review \& editing.. WV and SD: Laboratory work, Formal analysis, Software, Visualization, Graph development, Writing - review \& editing.

\section{Funding}

This study was supported by the Department of Biotechnology (BT/PR15038/TRM/120/59/2015), GOI.

\section{Declarations}

\section{Ethical considerations}

The present study of 100 days duration, including ten days adaptation period, was carried out as per the guidelines laid down by Institutional Animal Ethics Committee (Reg No. 1705/GO/ac/13/CPCSEA, Dt. 3/7/2013), ICAR-National Dairy Research Institute, Karnal, India (IAEC. No. 116/16, Dt. 3/12/2016).

\section{Conflict of interest}

The authors declare no competing interests.

\section{Data availability statement}

The authors affirm that the data supporting the current study's conclusions are found in the manuscript (and/or supplementary materials).

\section{References}

Abbeddou, S., Rischkowsky, B., Richter, E.K., Hess, H.D. and Kreuzer, M., 2011. Modification of milk fatty acid composition by feeding forages and agro-industrial byproducts from dry areas to Awassi sheep. Journal of Dairy Science, 94, 4657-4668.

Aebi, H., 1984. Catalase in vitro, Methods in Enzymology 105 Academic Press, 121-126.

Banakar, P.S., Sarkar, S., Tyagi, B., Vinay, V.V., Chugh, T., Kumar, S., Tyagi, N. and Tyagi, A.K., 2019. Effect of dietary plant secondary metabolites on rumen fermentation and microbial community: a review. Indian Journal of Animal Nutrition, 36, 107.

Benchaar, C., 2021. Diet supplementation with thyme oil and its main component thymol failed to favorably alter rumen fermentation, improve nutrient utilization, or enhance milk production in dairy cows. Journal of Dairy Science, 104, 324-336. 
Berchieri-Ronchi, C.B., Kim, S.W., Zhao, Y., Correa, C.R., Yeum, K.J. and Ferreira, A.L.A., 2011. Oxidative stress status of highly prolific sows during gestation and lactation. Animal, 5, 1774-1779.

Bradford, B.J., Yuan, K., Farney, J.K., Mamedova, L.K. and Carpenter, A.J., 2015. Invited review: Inflammation during the transition to lactation: New adventures with an old flame. Journal of Dairy Science, 98, 6631-6650.

Bruckmaier, R.M. and Gross, J.J., 2017. Lactational challenges in transition dairy cows. Animal Production Science, 57(7), 1471-1481.

Buccioni, A., Pallara, G., Pastorelli, R., Bellini, L., Cappucci, A., Mannelli, F., Minieri, S., Roscini, V., Rapaccini, S., Mele, M., Giovannetti, L., Viti, C. and Pauselli, M., 2017. Effect of dietary chestnut or quebracho tannin supplementation on microbial community and fatty acid profile in the rumen of dairy ewes. BioMed Research International., 1-12.

Buccioni, A., Pauselli, M., Viti, C., Minieri, S., Pallara, G., Roscini, V., Rapaccini, S., Marinucci, M.T., Lupi, P., Conte, G. and Mele, M., 2015. Milk fatty acid composition, rumen microbial population, and animal performances in response to diets rich in linoleic acid supplemented with chestnut or quebracho tannins in dairy ewes. Journal of Dairy Science, 98, 1145-1156.

Buccioni, A., Serra, A., Minieri, S., Mannelli, F., Cappucci, A., Benvenuti, D., Rapaccini, S., Conte, G. and Mele, M., 2015. Milk production, composition, and milk fatty acid profile from grazing sheep fed diets supplemented with chestnut tannin extract and extruded linseed. Small Ruminant Research, 130, 200207.

Colitti, M., Stefanon, B., Gabai, G., Gelain, M.E. and Bonsembiante, F., 2019. Oxidative stress and nutraceuticals in the modulation of the immune function: current knowledge in animals of veterinary interest. Antioxidants, 8(1), 28.

Correddu, F., Lunesu, M.F., Buffa, G., Atzori, A.S., Nudda, A., Battacone, G. and Pulina, G., 2020. Can agroindustrial by-products rich in polyphenols be advantageously used in the feeding and nutrition of dairy small ruminants?. Animals, 10(1), 131.

Danish P, Ali Q, Mm, H. and Malik A, n.d. Antifungal and antibacterial activity of aloe vera plant extract. Biological and Clinical Sciences Research Journal, 2020, e003.

Darabighane, B., Zarei, A., Shahneh, A.Z. and Mahdavi, A., 2011. Effects of different levels of Aloe vera gel as an alternative to antibiotic on performance and ileum morphology in broilers. Italian Journal of Animal Science, 10, e36.

Dschaak, C.M., Williams, C.M., Holt, M.S., Eun, J.S., Young, A.J. and Min, B.R., 2011. Effects of supplementing condensed tannin extract on intake, digestion, ruminal fermentation, and milk production of lactating dairy cows. Journal of Dairy Science, 94, 2508-2519. 
Frutos, P., Hervás, G., Giráldez, F.J. and Mantecón, A.R., 2004. Tannins and ruminant nutrition. Spanish Journal of Agricultural Research, 2, 191.

Frutos, P., Hervás, G., Natalello, A., Luciano, G., Fondevila, M., Priolo, A. and Toral, P.G., 2020. Ability of tannins to modulate ruminal lipid metabolism and milk and meat fatty acid profiles. Animal Feed Science and Technology, 269, 114623.

Garcia, S.N., Osburn, B.I. and Jay-Russell, M.T., 2020. One health for food safety, food security, and sustainable food production. Frontiers in Sustainable Food Systems, 4, 1.

Ghasemi-Sadabadi, M., Veldkamp, T., Van Krimpen, M., Ebrahimnezhad, Y., Ghalehkandi, J.G., Salehi, A., Didehvar, M., Khodaei, M. and Mehdizadeh, A., 2020. Determining tolerance of Japanese quail to different dietary fat peroxidation values by supplementation with Rosemary and Aloe Vera on performance and meat quality. Animal Feed Science and Technology, 267, 114574.

Ghiselli, A., Serafini, M., Natella, F. and Scaccini, C., 2000. Total antioxidant capacity as a tool to assess redox status: Critical view and experimental data. Free Radical Biology and Medicine, 29(11), 1106-1114.

Gross, J.J. and Bruckmaier, R.M., 2019. Invited review: Metabolic challenges and adaptation during different functional stages of the mammary gland in dairy cows: Perspectives for sustainable milk production. Journal of dairy science, 102(4), 2828-2843.

Heidarian Miri, V., Ebrahimi, S.H. and Kumar Tyagi, A., 2015. The effect of cumin (Cuminum cyminum) seed extract on the inhibition of PUFA biohydrogenation in the rumen of lactating goats via changes in the activity of rumen bacteria and linoleate isomerase enzyme. Small Ruminant Research, 125, 56-63.

Heidarian Miri, V., Tyagi, A.K., Ebrahimi, S.H. and Mohini, M., 2013. Effect of cumin (Cuminum cyminum) seed extract on milk fatty acid profile and methane emission in lactating goat. Small Ruminant Research, $113,66-72$.

Holtshausen, L., Chaves, A. V., Beauchemin, K.A., McGinn, S.M., McAllister, T.A., Odongo, N.E., Cheeke, P.R. and Benchaar, C., 2009. Feeding saponin-containing Yucca schidigera and Quillaja saponaria to decrease enteric methane production in dairy cows. Journal of Dairy Science, 92, 2809-2821.

Hristov, A.N., Lee, C., Cassidy, T., Heyler, K., Tekippe, J.A., Varga, G.A., Corl, B. and Brandt, R.C., 2013. Effect of Origanum vulgare L. leaves on rumen fermentation, production, and milk fatty acid composition in lactating dairy cows. Journal of Dairy Science, 96, 1189-1202.

Huang, Q., Liu, X., Zhao, G., Hu, T. and Wang, Y., 2018. Potential and challenges of tannins as an alternative to in-feed antibiotics for farm animal production. Animal Nutrition, 4(2), 137-150.

King, T., Cole, M., Farber, J.M., Eisenbrand, G., Zabaras, D., Fox, E.M. and Hill, J.P., 2017. Food safety for food security: Relationship between global megatrends and developments in food safety. Trends in Food Science and Technology, 68, 160-175.

Page $12 / 20$ 
Kumar, R., Singh, A.K., Gupta, A., Bishayee, A. and Pandey, A.K., 2019. Therapeutic potential of Aloe veraA miracle gift of nature. Phytomedicine, 60, 152996.

Lainé, N. and Morand, S., 2020. Linking humans, their animals, and the environment again: A decolonized and more-than-human approach to "one Health". Parasite, 27.

Landau, S., Perevolotsky, A., Bonfil, D., Barkai, D. and Silanikove, N., 2000. Utilization of low quality resources by small ruminants in Mediterranean agro-pastoral systems: The case of browse and aftermath cereal stubble. Livestock Production Science, 64, 39-49.

Liu, H.W., Zhou, D.W. and Li, K., 2013. Effects of chestnut tannins on performance and antioxidative status of transition dairy cows. Journal of Dairy Science, 96, 5901-5907.

Lucini, L., Pellizzoni, M., Pellegrino, R., Molinari, G. Pietro and Colla, G., 2015. Phytochemical constituents and in vitro radical scavenging activity of different Aloe species. Food Chemistry, 170, 501-507.

Maan, A.A., Nazir, A., Khan, M.K.I., Ahmad, T., Zia, R., Murid, M. and Abrar, M., 2018. The therapeutic properties and applications of Aloe vera: A review. Journal of Herbal Medicine, 12, 1-10.

Madesh, M. and Balasubramanian, K.A., 1998. Microtiter plate assay for superoxide dismutase using MTT reduction by superoxide. Indian Journal of Biochemistry and Biophysics, 35, 184-188.

Maheswari, M., Das, A., Datta, M. and Tyagi, A.K., 2021. Supplementation of tropical seaweed-based formulations improves antioxidant status, immunity and milk production in lactating Murrah buffaloes. Journal of Applied Phycology, 1-15.

Mann, A., Nehra, K., Rana, J.S. and Twinkle, 2021. Antibiotic resistance in agriculture: Perspectives on upcoming strategies to overcome upsurge in resistance. Current Research in Microbial Sciences, 2 , 100030.

Moate, P.J., Williams, S.R.O., Torok, V. a, Hannah, M.C., Ribaux, B.E., Tavendale, M.H., Eckard, R.J., Jacobs, J.L., Auldist, M.J. and Wales, W.J., 2014. Grape marc reduces methane emissions when fed to dairy cows. Journal of Dairy Science, 97, 5073-5087.

Paglia, D.E. and Valentine W.N., 1967. Studies on the quantitative and qualitative character- ization of erythrocyte glutathione peroxidase. Journal of Laboratory and Clinical Medicine, 70, 158-169

Patra, A.K. and Saxena, J., 2011. Exploitation of dietary tannins to improve rumen metabolism and ruminant nutrition. Journal of the Science of Food and Agriculture, 91(1), 24-37.

Prakova, Gospodinka, Vlaykova, Tatyana, Emin, S., Yordanova, K., Dimov, D., Ilieva, V., Koychev, A., Prakova, $\mathrm{G}$ and Vlaykova, T, 2010. Total antioxidant capacity of plasma determined as ferrous reducing ability of plasma in patients with COPD. Trakia Journal of Sciences, 8, 205-213. 
Qiao, G.H., Zhou, X.H., Li, Y., Zhang, H.S., Li, J.H., Wang, C.M. and Lu, Y., 2012. Effect of several supplemental Chinese herbs additives on rumen fermentation, antioxidant function and nutrient digestibility in sheep. Journal of Animal Physiology and Animal Nutrition, 96, 930-938.

Rana, M.S., Tyagi, A., Hossain, S.A. and Tyagi, A.K., 2012. Effect of tanniniferous Terminalia chebula extract on rumen biohydrogenation, \{increment\} 9-desaturase activity, CLA content and fatty acid composition in longissimus dorsi muscle of kids. Meat Science, 90, 558-563.

Rubió, L., Motilva, M.-J. and Romero, M.-P., 2013. Recent advances in biologically active compounds in herbs and spices: a review of the most effective antioxidant and anti-inflammatory active principles. Critical Reviews in Food Science and Nutrition, 53, 943-953.

Sánchez-Machado, D.I., López-Cervantes, J., Sendón, R. and Sanches-Silva, A., 2017. Aloe vera: Ancient knowledge with new frontiers. Trends in Food Science and Technology, 61, 94-102.

Santos, N.W., Yoshimura, E.H., Mareze-Costa, C.E., Machado, E., Agustinho, B.C., Pereira, L.M., Brito, M.N., Brito, N.A. and Zeoula, L.M., 2017. Supplementation of cow milk naturally enriched in polyunsaturated fatty acids and polyphenols to growing rats. PLoS ONE, 12, 1-13.

Sharma, N., Singh, N.K., Singh, O.P., Pandey, V. and Verma, P.K., 2011. Oxidative stress and antioxidant status during transition period in dairy cows. Asian-Australasian Journal of Animal Sciences, 24, 479484.

Singh, M., Kumar, S., Banakar, P.S., Vinay, V.V., Das, A., Tyagi, N. and Tyagi, A.K., 2021a. Synbiotic formulation of Cichorium intybus root powder with Lactobacillus acidophilus NCDC15 and Lactobacillus reuteri BFE7 improves growth performance in Murrah buffalo calves via altering selective gut health indices. Tropical Animal Health and Production, 53.

Singh, A., Kumar, S., Vinay, V.V., Tyagi, B., Choudhury, P.K., Rashmi, H.M., Banakar, P.S., Tyagi, N. and Tyagi, A.K., 2021b. Autochthonous Lactobacillus spp. isolated from Murrah buffalo calves show potential application as probiotic. Current Research in Biotechnology, 3, 109-119.

Sordillo, L.M. and Aitken, S.L., 2009. Impact of oxidative stress on the health and immune function of dairy cattle. Veterinary Immunology and Immunopathology, 128, 104-109.

Suman, M., Tyagi, A.K. and Phondba, B.T., 2015. Polyphenols rich plants extract supplementation to enhance the desaturation and antioxidant activity in goat kids. Indian Journal of Animal Sciences, 85, 593-600.

Tekippe, J.A., Hristov, A.N., Heyler, K.S., Cassidy, T.W., Zheljazkov, V.D., Ferreira, J.F.S., Karnati, S.K. and Varga, G.A., 2011. Rumen fermentation and production effects of Origanum vulgare L. leaves in lactating dairy cows. Journal of Dairy Science, 94, 5065-5079. 
Toral, P.G., Hervás, G., Bichi, E., Belenguer, Á. and Frutos, P., 2011. Tannins as feed additives to modulate ruminal biohydrogenation: Effects on animal performance, milk fatty acid composition and ruminal fermentation in dairy ewes fed a diet containing sunflower oil. Animal Feed Science and Technology, 164, 199-206.

Zhong, R.Z., Yu, M., Liu, H.W., Sun, H.X., Cao, Y. and Zhou, D.W., 2012. Effects of dietary Astragalus polysaccharide and Astragalus membranaceus root supplementation on growth performance, rumen fermentation, immune responses, and antioxidant status of lambs. Animal Feed Science and Technology, $174,60-67$.

Zhou, L., Wang, D., Hu, H. and Zhou, H., 2020. Effects of Piper sarmentosum extract supplementation on growth performances and rumen fermentation and microflora characteristics in goats. Journal of Animal Physiology and Animal Nutrition, 104, 431-438.

\section{Tables}

Table 1 Ingredients composition of the diet (on DM basis)

\begin{tabular}{|llll}
\hline Ingredients (parts) & AV0 & AV2 & AV4 \\
\hline Concentrate mixture: 40 & & & \\
\hline Maize & 33 & 33 & 33 \\
\hline Groundnut cake & 18 & 18 & 18 \\
\hline Mustard oil cake & 10 & 10 & 10 \\
\hline Cottonseed cake (decorticated) & 5 & 5 & 5 \\
\hline Bajra & 20 & 20 & 20 \\
\hline Wheat Bran & 6 & 6 & 6 \\
\hline De-oiled rice bran & 5 & 5 & 5 \\
\hline Mineral Mixture & 2 & 2 & 2 \\
\hline Common salt & 1 & 1 & 1 \\
\hline Green fodder (Berseem): 60 & & & \\
\hline Extract Supplement & & & \\
\hline Aloe vera plant extract (\%) & 0 & 2 & 4 \\
\hline
\end{tabular}

Table 2 Chemical composition of diets (\% DM basis) 


\begin{tabular}{lll} 
Nutrients & Berseem & Concentrate \\
\hline Dry matter (DM) & $16.18 \pm 0.37$ & $89.95 \pm 0.39$ \\
\hline Organic matter (OM) & $90.87 \pm 0.2$ & $92.63 \pm 0.52$ \\
\hline Crude protein (CP) & $16.71 \pm 0.17$ & $17.62 \pm 0.36$ \\
\hline Ether extract (EE) & $2.45 \pm 0.04$ & $3.67 \pm 0.04$ \\
\hline Neutral detergent fibre (NDF) & $53.305 \pm 0.5$ & $30.72 \pm 0.4$ \\
\hline Acid detergent fibre (ADF) & $30.52 \pm 0.34$ & $14.05 \pm 0.14$ \\
\hline Crude fibre (CF) & $25.96 \pm 0.23$ & $7.54 \pm 0.23$ \\
\hline Total ash (TA) & $9.045 \pm 0.12$ & $7.37 \pm 0.52$
\end{tabular}

Table 3 Nutrient utilization in goats with supplementation of aloe vera extract ${ }^{*}$

\begin{tabular}{llllll} 
Attributes & AV0 & AV2 & AV4 & SEM & Significance \\
\hline Nutrient intake (g/d) & & & & & \\
\hline DM (kg/100kg BW) & 3.69 & 3.80 & 3.76 & 0.034 & 0.270 \\
\hline DM (g/kg W^0.75) & 92.16 & 93.92 & 93.02 & 0.847 & 0.467 \\
\hline OM & 1334.90 & 1322.20 & 1312.60 & 18.23 & 0.670 \\
\hline CP & 274.83 & 274.5 & 275.95 & 2.153 & 0.816 \\
\hline NDF & 668.96 & 676.16 & 679.99 & 6.934 & 0.580 \\
\hline ADF & 305.43 & 311.9 & 312.56 & 6.057 & 0.684 \\
\hline EE & 41.83 & 41.55 & 42.02 & 0.255 & 0.515 \\
\hline Apparent digestibility of nutrients $(\%)$ & & & \\
\hline DM & 65.84 & 66.11 & 67.22 & 0.373 & 0.170 \\
\hline OM & 67.14 & 67.80 & 68.86 & 0.338 & 0.246 \\
\hline CP & 68.83 & 68.74 & 69.25 & 0.459 & 0.704 \\
\hline NDF & 57.05 & 57.88 & 58.19 & 0.390 & 0.293 \\
\hline ADF & 37.63 & 38.87 & 38.45 & 0.342 & 0.184 \\
\hline EE & 75.91 & 75.73 & 76.37 & 0.331 & 0.503 \\
\hline
\end{tabular}

${ }^{¥} \mathrm{AVO}=0 \%$ Aloe vera extract; $\mathrm{AV} 2=2 \%$ Aloe vera extract; $\mathrm{AV} 4=4 \%$ Aloe vera extract. $\mathrm{SEM}=$ standard error of means. 


\begin{tabular}{llllllll} 
& & & & & D & P & T*P \\
\hline $\begin{array}{l}\text { Dry matter intake } \\
\text { (kg/100 kg BW) }\end{array}$ & 3.97 & 3.94 & 3.96 & 0.018 & 0.779 & $<0.001$ & 0.037 \\
\hline $\begin{array}{l}\text { Metabolic Bodyweight, } \\
\text { BW^0.75 (Kg) }\end{array}$ & $15.29^{\mathrm{a}}$ & $15.25^{\mathrm{a}}$ & $14.61^{\mathrm{b}}$ & 0.179 & 0.002 & 0.026 & 0.998 \\
\hline Milk yield (g/d) & $1566.78^{\mathrm{b}}$ & $1582.96^{\mathrm{b}}$ & $1670.09^{\mathrm{a}}$ & 11.82 & 0.001 & $<0.001$ & 0.051 \\
\hline Milk fat (g/d) & $59.95^{\mathrm{b}}$ & $60.13^{\mathrm{b}}$ & $63.86^{\mathrm{a}}$ & 0.012 & $<0.001$ & $<0.001$ & $<0.001$ \\
\hline Milk protein (g/d) & $57.72^{\mathrm{b}}$ & $58.55^{\mathrm{b}}$ & $61.63^{\mathrm{a}}$ & 0.018 & $<0.001$ & $<0.001$ & 0.033 \\
\hline Milk lactose (g/d) & $78.74^{\mathrm{b}}$ & $79.97^{\mathrm{b}}$ & $83.95^{\mathrm{a}}$ & 0.019 & $<0.001$ & $<0.001$ & 0.047 \\
\hline Milk solid not fat (g/d) & $123.26^{\mathrm{b}}$ & $125.20^{\mathrm{b}}$ & $131.41^{\mathrm{a}}$ & 0.069 & $<0.001$ & $<0.001$ & 0.050
\end{tabular}

${ }^{¥} \mathrm{AVO}=0 \%$ Aloe vera extract; $\mathrm{AV} 2=2 \%$ Aloe vera extract; $\mathrm{AV} 4=4 \%$ Aloe vera extract. $\mathrm{SEM}=$ standard error of means. Means with different superscripts in a row differ significantly $(P<0.05)$. D: Diet effect; P: Period effect.

Table 5 Erythrocyte antioxidant enzyme activity and plasma FRAP level of lactating goats in different treatment diets ${ }^{*}$.

\begin{tabular}{|c|c|c|c|c|c|c|c|}
\hline \multirow[t]{2}{*}{ Attribute } & \multirow[t]{2}{*}{ AVO } & \multirow[t]{2}{*}{ AV2 } & \multirow[t]{2}{*}{ AV4 } & \multirow[t]{2}{*}{ SEM } & \multicolumn{3}{|c|}{ Significance } \\
\hline & & & & & D & $\mathbf{P}$ & $\mathrm{T} * \mathrm{P}$ \\
\hline $\mathrm{SOD}(\mathrm{U} / \mathrm{mg} \mathrm{Hb})$ & $99.91^{\mathrm{b}}$ & $105.72^{a}$ & $112.14^{\mathrm{a}}$ & 0.760 & $<0.001$ & $<0.001$ & 0.004 \\
\hline $\begin{array}{l}\text { Catalase }(\mu \text { moles of } \\
\mathrm{H} 2 \mathrm{O} 2 \text { consumed } / \mathrm{min} / \mathrm{g} \mathrm{Hb} \text { ) }\end{array}$ & $51.22^{b}$ & $56.13^{\mathrm{a}}$ & $56.98^{a}$ & 0.828 & $<0.001$ & $<0.001$ & 0.002 \\
\hline $\begin{array}{l}\text { GPx }(\mu \mathrm{mol} \text { of NADPH } \\
\text { oxidised } / \mathrm{g} \mathrm{Hb} / \mathrm{min})\end{array}$ & 15.41 & 15.84 & 15.26 & 0.271 & 0.709 & 0.534 & 0.997 \\
\hline FRAP $[\mathrm{mmol} / \mathrm{L}(\mathrm{mM}) \mathrm{Fe} 2+]$ & $266.15^{b}$ & $284.3^{a}$ & $286.62^{\mathrm{a}}$ & 4.305 & $<0.001$ & $<0.001$ & $<0.001$ \\
\hline
\end{tabular}

${ }^{¥} \mathrm{AV} 0=0 \%$ Aloe vera extract; $\mathrm{AV} 2=2 \%$ Aloe vera extract; $\mathrm{AV} 4=4 \%$ Aloe vera extract. SOD: Superoxide Dismutase; GPx: Glutathione Peroxidase; and FRAP: Ferric Reducing total Antioxidant Power. SEM= standard error of means. Means with different superscripts in a row differ significantly $(P<0.05)$. D: Diet effect; P: Period effect.

Table 6 Individual volatile fatty acid content in rumen liquor and pH of rumen of goats supplemented with aloe vera extract ${ }^{*}$ 


\begin{tabular}{|llllll|}
\hline VFA (mmol/L) & AV0 & AV2 & AV4 & SEM & Significance \\
\hline $\mathrm{pH}$ & 6.7025 & 6.6875 & 6.775 & 0.034 & 0.979 \\
\hline Acetic acid (C2) & 129.67 & 129.08 & 127.13 & 0.811 & 0.449 \\
\hline Propionic acid (C3) & $38.25^{\mathrm{b}}$ & $41.67^{\mathrm{a}}$ & $43.03^{\mathrm{a}}$ & 0.808 & 0.024 \\
\hline Butyric acid (C4) & 1.59 & 1.63 & 1.57 & 0.030 & 0.864 \\
\hline C2:C3 & $3.38^{\mathrm{a}}$ & $3.12^{\mathrm{ab}}$ & $2.96^{\mathrm{b}}$ & 0.073 & 0.037 \\
\hline
\end{tabular}

${ }^{¥} \mathrm{AV} 0=0 \%$ Aloe vera extract; $\mathrm{AV} 2=2 \%$ Aloe vera extract; $\mathrm{AV} 4=4 \%$ Aloe vera extract. $\mathrm{SEM}=$ standard error of means. Means with different superscripts in a row differ significantly $(P<0.05)$.

Figures

A)

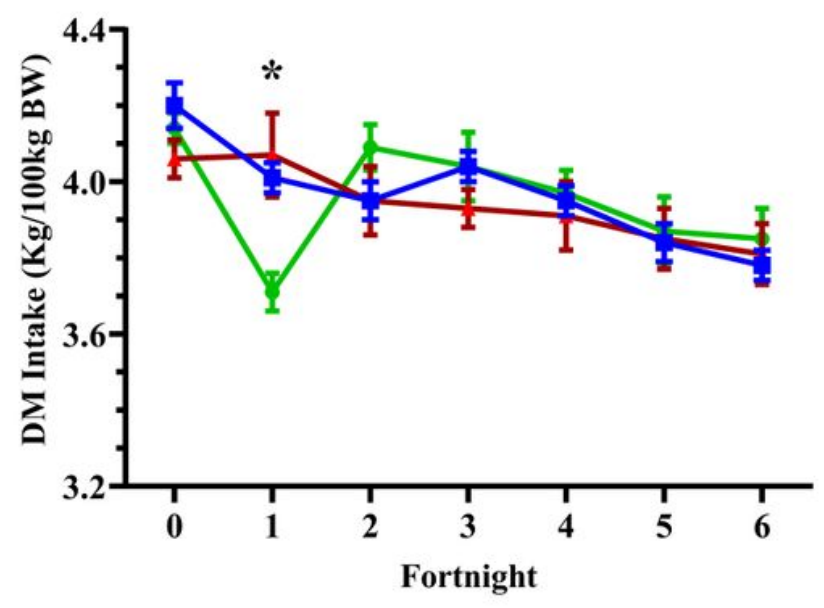

B)

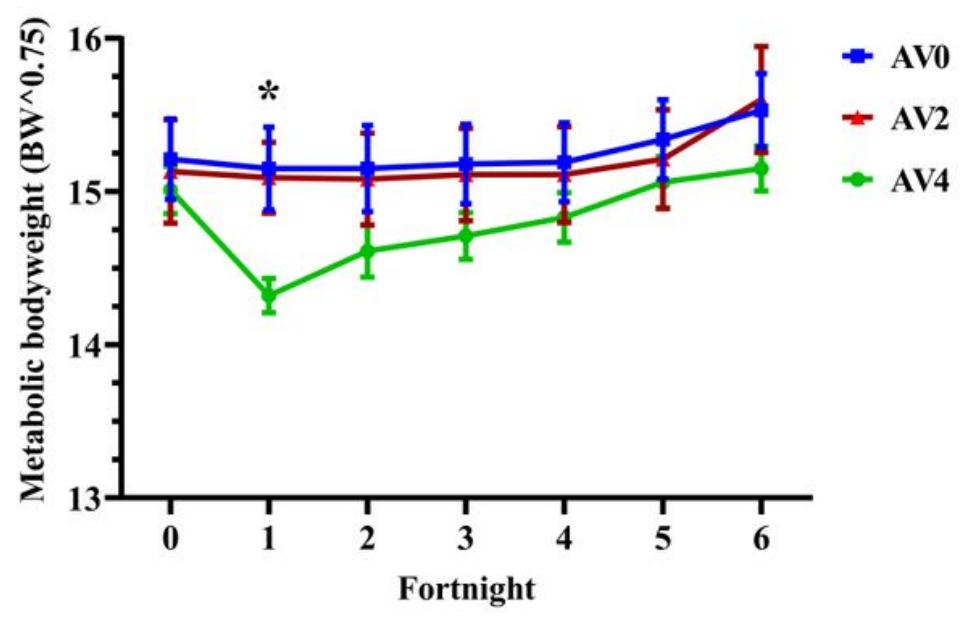

Figure 1

Periodic changes in the dry matter intake and metabolic bodyweight changes of lactating goats in different treatment diets. $A V 0=0 \%$ Aloe vera extract; $A V 2=2 \%$ Aloe vera extract; $A V 4=4 \%$ Aloe vera extract. Values are expressed as mean \pm SEM. 


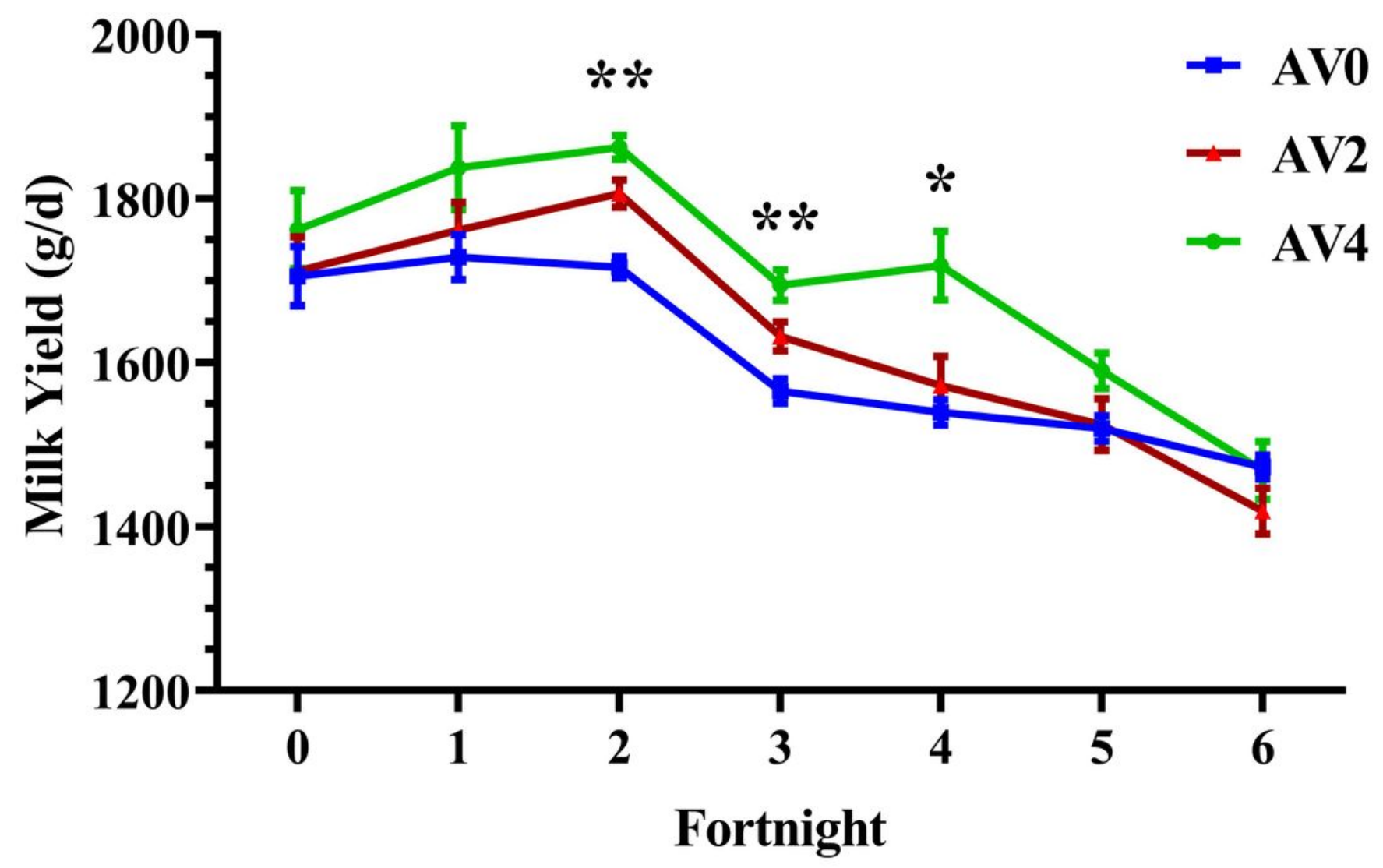

Figure 2

Periodic changes in the milk yield of lactating goats in different treatment diets. AVO $=0 \%$ Aloe vera extract; $\mathrm{AV} 2=2 \%$ Aloe vera extract; $\mathrm{AV} 4=4 \%$ Aloe vera extract. Values are expressed as mean $\pm \mathrm{SEM}$. 
A)

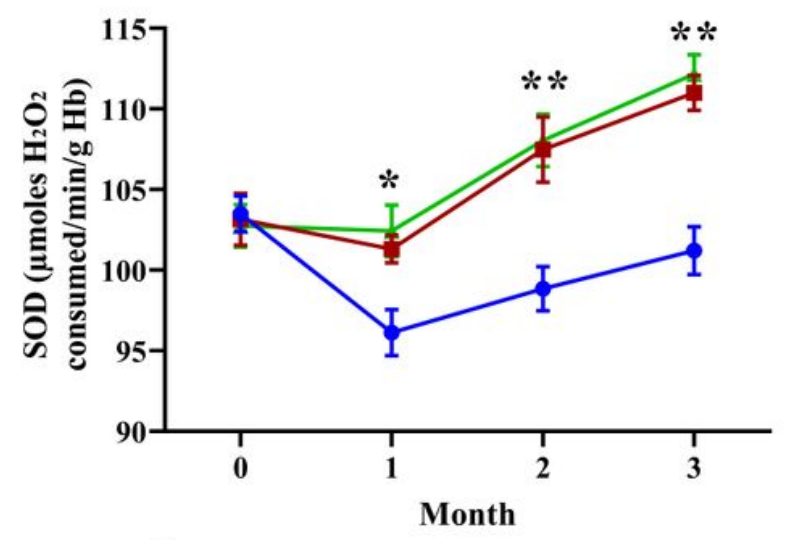

C)

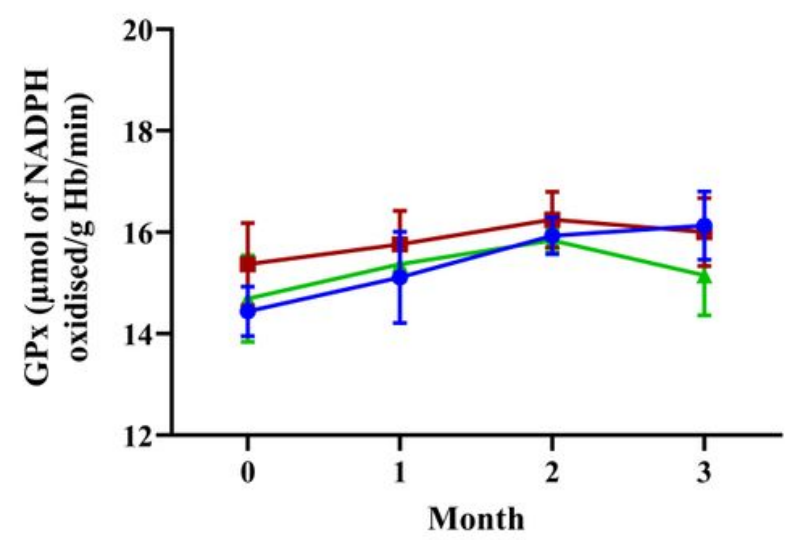

B)

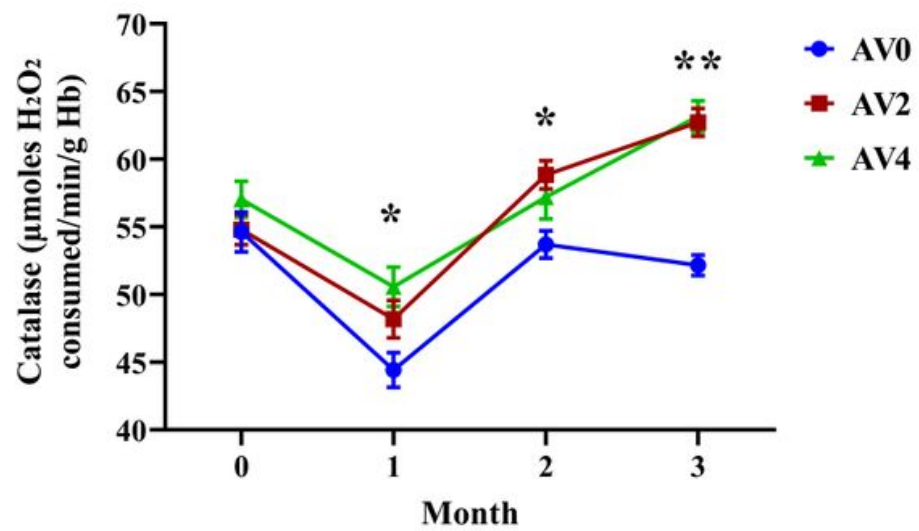

D)

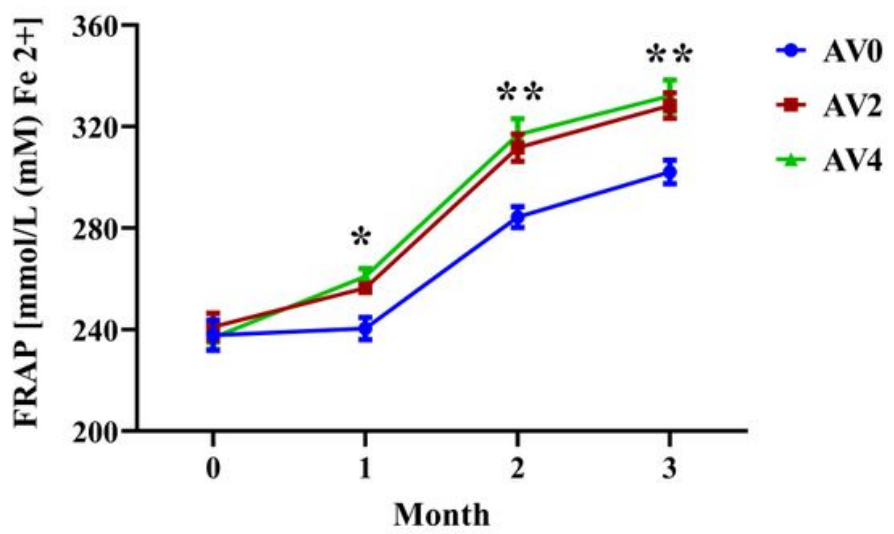

Figure 3

Periodic changes in the erythrocyte antioxidant enzyme activity A) SOD: Superoxide Dismutase, B) Catalase, C) GPx: Glutathione Peroxidase and D) Plasma FRAP (Ferric Reducing total Antioxidant Power) level of lactating goats in different treatment diets. AVO $=0 \%$ Aloe vera extract; $A V 2=2 \%$ Aloe vera extract; $A \bigvee 4=4 \%$ Aloe vera extract. Values are expressed as mean \pm SEM. 